\title{
Article \\ Cutting Force Transition Model Considering the Influence of Tool System by Using Standard Test Table
}

\author{
Xi Chen, Dinghua Zhang and Qi Wang *
}

check for

updates

Citation: Chen, X.; Zhang, D.; Wang, Q. Cutting Force Transition Model Considering the Influence of Tool System by Using Standard Test Table. Sensors 2021, 21, 1340. https:// doi.org/10.3390/s21041340

Academic Editor: Bijan Shirinzadeh Received: 28 January 2021

Accepted: 9 February 2021

Published: 13 February 2021

Publisher's Note: MDPI stays neutral with regard to jurisdictional claims in published maps and institutional affiliations.

Copyright: (c) 2021 by the authors. Licensee MDPI, Basel, Switzerland. This article is an open access article distributed under the terms and conditions of the Creative Commons Attribution (CC BY) license (https:// creativecommons.org/licenses/by/ $4.0 /)$.
The Key Laboratory of High Performance Manufacturing for Aero Engine, Northwestern Polytechnical University, Ministry of Industry and Information Technology, Xi'an 710072, China; chenxi15@mail.nwpu.edu.cn (X.C.); dhzhang@nwpu.edu.cn (D.Z.)

* Correspondence: wangqi8967@mail.nwpu.edu.cn

\begin{abstract}
The cutting force prediction model usually uses the classical oblique transformation method, which introduces the orthogonal cutting parameters into the oblique milling edge shape, and combines the geometric parameters of the tool to convert the orthogonal cutting force into the actual cutting force, thereby predicting the cutting force. However, this cutting force prediction method ignores the impact of tool vibration in actual machining, resulting in a large difference between the prediction model and the actual measurement. This paper proposes a cutting force conversion model considering the influence of the tool system. The proposed model fully considers the impact of tool vibration on the cutting force. On the basis of the orthogonal model, superimposing the additional cutting force generated by tool vibration makes the predicted value of the model closer to the actual cutting force. The results of milling experiments show that the conversion model can obtain higher prediction accuracy. Moreover, compared with the original conversion model, the accuracy of the proposed model is significantly improved.
\end{abstract}

Keywords: milling; standard test table; cutting force transition; data application

\section{Introduction}

Machining is an important method in producing aeroengine parts, which is widely used in aerospace components processing [1]. The design and optimization of all aspects of the cutting process [2] are closely related to production quality and are the key to improve efficiency and reduce costs. Therefore, monitoring and analysis of machining process parameters are needed to avoid tool wear and improve machining quality. Research on machining process information usually studies cutting forces [3] or system dynamics [4].

The cutting force generated by the machining process of the machine tool is related to the machining state. Cutting force signal is a physical quantity commonly used in machining, which is used to evaluate the machining process and quality [5-7]. It is very important to obtain accurate cutting force to research chatter, overload, and tool wear [8]. Taner et al. [9] proposed a widely used cutting force model which can predict cutting force by identifying cutting force coefficients. Zhu et al. $[10,11]$ proposed a method to analyze tool positioning changes and tool runout by calculating the undeformed cutting thickness and improved the model in subsequent research. Sun et al. [12] proposed a dynamic milling parameter prediction model considering the influence of deformation. The thin-walled parts and cutting tools were discretized into micro elements, and their dynamic effects were analyzed in each contact area. Based on the instantaneous cutting force model of tool contact point and the stiffness of machining system, Sahoo et al. [13] studied the influence of tool meshing area on cutting force. According to the tool path and the corresponding cutting force, Zhang et al. [14] proposed an efficient calibration procedure for cutter runout parameters and specific cutting force coefficients, which was an accurate prediction method for cutting force in 5-axis flank milling of a sculptured surface. Li et al. [15] proposed a dynamic model considering the cutting insert engagement based 
on the geometric characteristics of the workpieces and the tool path, which can overcome the poor accuracy of chatter prediction as well as the waste of processing efficiency. Wang et al. [16] and Zhu et al. [17] solved the differential equation by using the measured modal parameters to obtain the tool vibration information or vibration information per tooth during the machining process, which was superimposed on the feed rate to predict the cutting force. However, these cutting force models are used to predict the cutting force under specific processing conditions through experiments. When the processing conditions change, a lot of experiments are needed to calibrate the model coefficients, which makes the model coefficients unable to use directly. The main reason for this phenomenon is the influence of tool system modal information, measuring equipment, and the machine tool processing system.

The research on tool system dynamics [18] and machine tool performance [19] has received more attention. The performance of the machine tool is very important to the improvement of machining quality and efficiency [20]. The finite element method is used to establish a model close to the real machine tool structure, analyze its performance, and achieve the purpose of improving efficiency. In order to analyze more accurately, Zhang et al. [21] proposed the substructure response analysis method. The machine tool as a whole is regarded as the coupling of single parts, thus the dynamic information of the tool tip can be found. Ji et al. [22] proposed a tool tip dynamic characteristic prediction method, which considered the contact dynamic characteristics between the tool and the tool holder, using the existing tool hammer test and finite element model to predict the dynamic characteristics of the new tool tip. This method can not only predict the performance of the machine tool, but also be more convenient for the performance analysis of the machine tool with the tool spindle combination changed. Chen et al. [23] and Liu et al. [24] combined substructure coupling with deep learning and used the transfer learning method to predict tool tip dynamic information at different positions. The existing modal [25] analysis methods are limited to the static conditions of machine tools, and most of them are applied to the transition of machining state, and few of them are used to analyze the influence of cutting force. The working modal analysis is adapted to characterize the dynamic characteristics of the machine tool under working conditions. Therefore, it is necessary to study the dynamic characteristics of machine tools for machining process.

In the machining of thin-walled components with difficult to machine materials, the actual cutting conditions are closely related to materials, structures, processing, and processes [26,27]. At present, the problem of obtaining cutting parameters is that the data acquisition conditions [28,29] are different, which cannot be directly applied and compared in the heterogeneous process system of material structure process. Therefore, it is necessary to solve the unity, comparability, and generality of basic cutting data acquisition. However, the current basic cutting experiment data acquisition is mainly for limited specific parameters [30], such as cutting force, lack of sufficient physical data. In addition, various test equipment [31-33] and external environment interference during the test process affect the observation test results, which results in inaccurate data sources, large errors and low reliability of simulation results in the physical simulation of the cutting process.

This paper proposed a cutting force transition model considering the influence of a tool system. The standard cutting force obtained by the standard test table can be converted into the milling force in the actual milling process. Firstly, obtain the standard cutting force under the self-developed standard test table. Secondly, the dynamic parameters of the milling tool are tested on the machine tool through the hammer test, and the corresponding acceleration signal during the cutting process is measured. Finally, the standard cutting force is combined with the tool dynamic parameters, and the cutting force in the actual milling process is predicted through the proposed model. The experimental results show that the results are basically consistent, indicating the reliability of the method. 


\section{Transition Model of Standard Cutting Force under Standard Test Table}

In the steady state cutting process, as the material is removed, the force acting on the workpiece can be divided into tangential force $F_{t}$ and radial force $F_{f}$. The forces under different cutting parameters can be expressed as follows:

$$
\left\{\begin{array}{l}
F_{t}=K_{t c} b h+K_{t e} b \\
F_{f}=K_{f c} b h+K_{f e} b
\end{array}\right.
$$

where, $K_{t c}$ and $K_{t e}$ are the tangential cutting force coefficients, $K_{f c}$ and $K_{f e}$ are the feed cutting coefficients, $b$ is the cutting width, $h$ is the cutting depth.

When the relationship between orthogonal cutting and milling is established, the cutting force coefficients are considered to be constant, and it can be regarded as only related to the material characteristics of the workpiece. When it is applied to the milling force model, the cutting force of milling can be obtained.

The cutting force of workpiece in milling can be divided into three directions: tangential force $F_{t}$, radial force $F_{r}$, and axial force $F_{a}$, as shown in Figure 1, these three forces could be expressed as follows:

$$
\left\{\begin{array}{l}
d F_{i, j, t}(\phi)=\left[K_{t c} h(\phi)+K_{t e}\right] d z \\
d F_{i, j, r}(\phi)=\left[K_{r c} h(\phi)+K_{r e}\right] d z \\
d F_{i, j, a}(\phi)=\left[K_{a c} h(\phi)+K_{a e}\right] d z
\end{array}\right.
$$

where, $\phi$ is the instantaneous rotatory angle of cutter. $h(\phi)$ is the instantaneous undeformed chip thickness on the jth disk of ith tooth. It can be expressed as follows:

$$
h(\phi)=f_{z} \sin (\phi)
$$

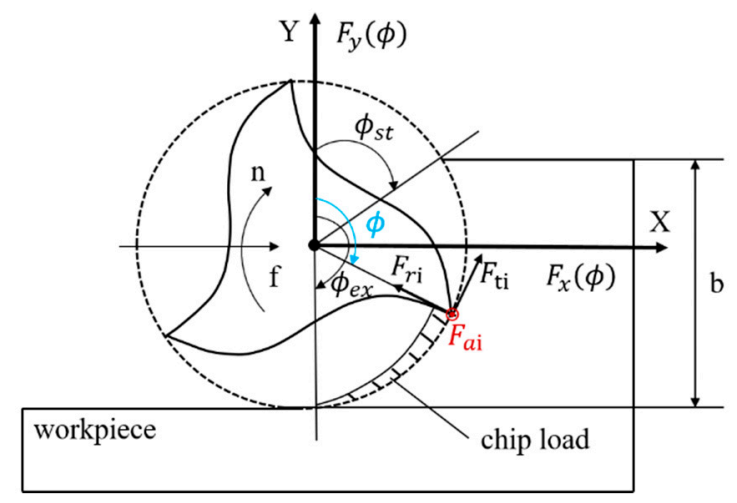

Figure 1. Geometry of milling process.

Transform cutting forces into static coordinate system by following equation:

$$
\left[\begin{array}{l}
d F_{i, j, x}(\phi) \\
d F_{i, j, y}(\phi) \\
d F_{i, j, z}(\phi)
\end{array}\right]=\left[\begin{array}{ccc}
-\cos \phi & -\sin \phi & 0 \\
\sin \phi & -\cos \phi & 0 \\
0 & 0 & 1
\end{array}\right]\left[\begin{array}{l}
d F_{i, j, t}(\phi) \\
d F_{i, j, r}(\phi) \\
d F_{i, j, a}(\phi)
\end{array}\right]
$$

where, $d F_{i, j, x}(\phi)$ is differential feed force, $d F_{i, j, y}(\phi)$ is differential normal force. $d F_{i, j, z}(\phi)$ is differential axial force. After a period of time, the sum of the forces acting on the tool can be expressed as follows:

$$
\left[\begin{array}{l}
F_{x}(\phi) \\
F_{y}(\phi) \\
F_{z}(\phi)
\end{array}\right]=\sum_{i=1}^{N} \sum_{j=1}^{M} g(\theta)\left[\begin{array}{l}
d F_{i, j, x}(\phi) \\
d F_{i, j, y}(\phi) \\
d F_{i, j, z}(\phi)
\end{array}\right]
$$


with:

$$
g(\theta)=\left\{\begin{array}{c}
1, \text { if } \phi_{s t}<\theta<\phi_{e x} \\
0, \text { otherwise. }
\end{array}\right.
$$

where, $\phi_{s t}$ is the entry angle and $\phi_{e x}$ is the exit angle.

\section{Cutting Force Transition Model Considering Tool System Influence}

As mentioned above, the cutting force coefficients identified on the standard test table can be considered to be obtained by the steady state cutting process. In steady state cutting, these parameters, such as cutting parameters $\left(v, f, a_{p}\right)$, cutting layer parameters, tool angle are considered to be basically unchanged, but when the cutting process occurs impact and vibration, the above parameters change greatly with time. Under the cutting chatter condition, the tool workpiece angle, chip cross-section, tool and workpiece contact friction state, shear angle are all changed at any time, which caused the change of cutting force.

In the dynamic cutting process, due to factors such as tool vibration and workpiece material unevenness, the cutting force is not constant, but changes with time. Therefore, the cutting force can be divided into steady cutting force $F_{m}$ and dynamic cutting force changes with time $d F(t)$, that is,

$$
F(t)=F_{m}+d F(t)
$$

During the dynamic cutting process, relative vibration occurs between the tool and the workpiece. The vibration can be divided into two components: one is that the component with the same direction of cutting speed changes the cutting speed between $v+d v$ and $v-d v$, and changes the relative friction between the flank and the workpiece; the other is the component with the same direction as the feed speed causes the chip thickness to change in $h_{c}+d h_{c}$ and $h_{c}-d h_{c}$, resulting in a feed rate of $v_{f}+d v_{f}$ and $v_{f}-d v_{f}$. Each of the above changes can make the cutting force change in different degrees. No matter whether only considering one of them, or also considering some changes; meanwhile, the cutting force is always in $F_{m}+d F$ and $F_{m}-d F$. Therefore, the dynamic cutting force can be expressed as follows:

$$
d F=K_{1} d h_{c}+K_{2} d v_{f}+K_{3} d v
$$

where, $K_{1}=\left.\frac{\partial \mathrm{dF}}{\partial d h_{c}}\right|_{d v_{f}=\mathrm{dv}=0^{\prime}} K_{2}=\left.\frac{\partial \mathrm{dF}}{\partial d v_{f}}\right|_{d h_{c}=\mathrm{dv}=0^{\prime}} K_{3}=\left.\frac{\partial \mathrm{dF}}{\partial \mathrm{dv}}\right|_{d h_{c}=d v_{f}=0^{\prime}}, K_{1}$ is the influence coefficient of chip thickness, $K_{2}$ is the influence coefficient of feed speed, $K_{3}$ is the influence coefficient of cutting speed.

In dynamic cutting, the variation of cutting speed depends on the vibration direction. If the vibration only occurs in the cutting direction, the vibration displacement will not change the cutting speed, but only change the chip thickness and feed rate. However, it is difficult to obtain the change of feed rate in the actual machining process, the dynamic cutting force can be simplified as only considering the change of chip thickness. Due to the stiffness of the spindle tool system, vibration will occur between the tool and workpiece, which will cause the change of chip thickness. Theoretically, the machine tool has vibration in three directions. The machine used in the experiment has stable axial stiffness, and the axial vibration can be ignored, see Figure 2. Base on this, the system can be simplified described as follows:

$$
M a_{\Delta}(t)+C v_{\Delta}(t)+K X_{\Delta}(t)=F_{\Delta}(t)
$$


where, $M=\left[\begin{array}{cc}m_{x} & 0 \\ 0 & m_{y}\end{array}\right], C=\left[\begin{array}{cc}c_{x} & 0 \\ 0 & c_{y}\end{array}\right], K=\left[\begin{array}{cc}k_{x} & 0 \\ 0 & k_{y}\end{array}\right], a_{\Delta}(t)=\left[\begin{array}{l}a_{\Delta x}(t) \\ a_{\Delta y}(t)\end{array}\right], v_{\Delta}(t)=$ $\left[\begin{array}{l}v_{\Delta x}(t) \\ v_{\Delta y}(t)\end{array}\right], X_{\Delta}(t)=\left[\begin{array}{l}x_{\Delta}(t) \\ y_{\Delta}(t)\end{array}\right], F_{\Delta}(t)=\left[\begin{array}{l}F_{\Delta x}(t) \\ F_{\Delta y}(t)\end{array}\right]$

Tool vibration bringing variation of the undeformed cutting thickness that directly influences the dynamic fluctuation of cutting forces. To take this influence into account in the calculation of cutting forces, an additional displacement could be added to the ideal cutting thickness:

$$
x_{\Delta}(t)=x(t)-h(t)
$$

where, $x(t)$ is obtained by acceleration signals. $h(t)$ is the ideal cutting thickness.

The cutting force obtained by cutting force coefficients can be regarded as the standard cutting force, and the predicted cutting force can be obtained by adding the influence of the tool system, which can be described as follows:

$$
F_{\text {standard }}(t)+F_{\Delta}(t)=F_{\text {predicted }}(t)
$$

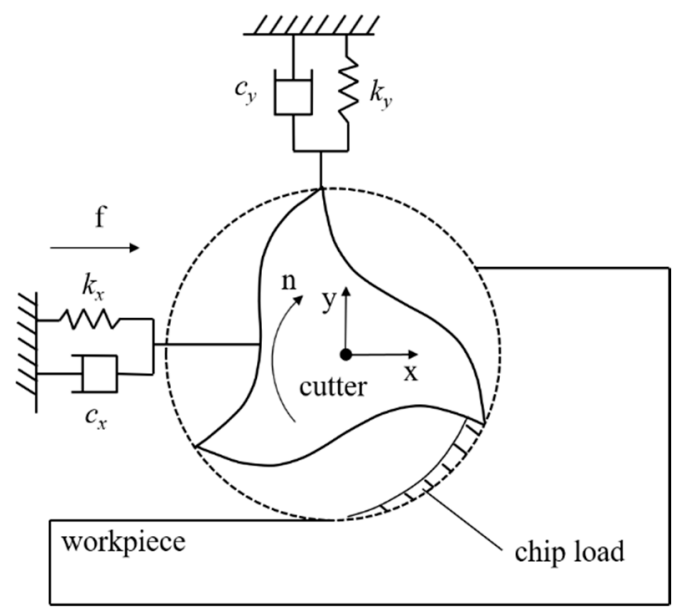

Figure 2. Milling cutter with two-degree freedom.

The flowchart of the proposed model calculation method is shown in Figure 3. The specific steps are as follows: (1) Carry out orthogonal cutting test on the self-developed standard test table to collect cutting force data as the basis of data conversion; (2) When converting from orthogonal cutting to milling, not only should the cutting force be mathematically integrated in the feed direction and axial direction, but also the influence of the tool system should be considered, and the tool dynamic parameters can be obtained by hammering test; (3) Using acceleration sensor to obtain tool displacement signal, combined with the dynamic equation, the predicted cutting force can be obtained by adding standard cutting force; (4) The accuracy of the cutting force conversion model is verified by comparing the measured force with the predicted force by experiments. 


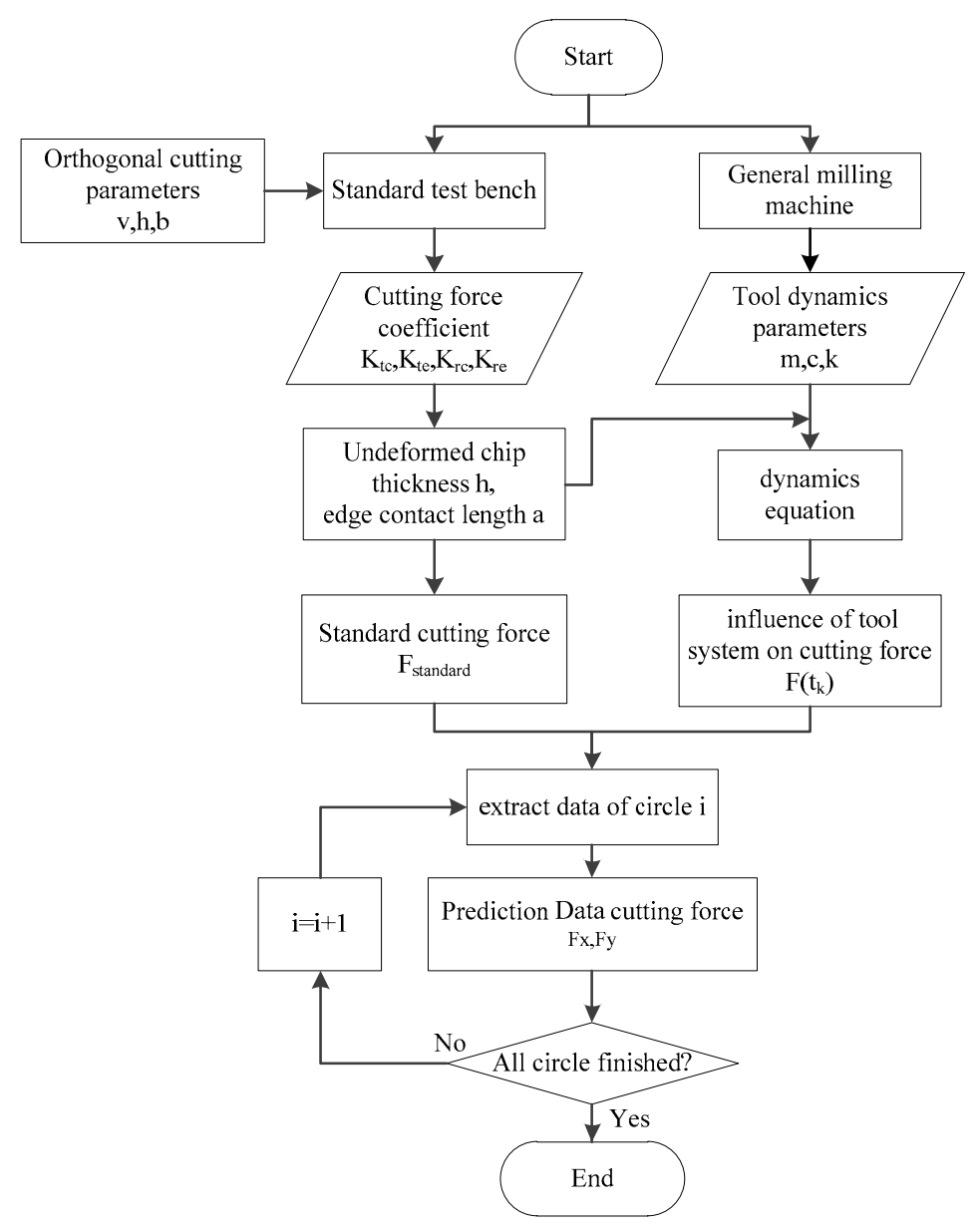

Figure 3. Flow chart of algorithm.

\section{Experimental Verification and Discussion}

\subsection{Data Collection of Cutting Force and Identification of Cutting Force Coefficients}

The orthogonal cutting experiment was carried out on the self-developed standard test table to obtain the standard cutting force data. The standard test table mainly consists of a tool and workpiece clamping module, motion control module, force acquisition module, and other parts. As shown in Figure 4, the standard test table can easily simulate orthogonal cutting. Its main principle is to convert the rotation of the motor into lateral movement. The workpiece holder on the moving table moves horizontally on the guide rail and fix the workpiece on the guide rail. The tool on the cross table produces relative movement, thus forming an orthogonal cutting process. The cutting thickness is adjusted by the inclined cross table at the bottom, and the cutting speed $v$ is controlled by changing the pulse number of the servo motor per second. Kistler 9347C is a triaxial force transducer which is under the tool. The workpiece material is aluminum alloy 7475, which is the most widely used nonferrous metal material in modern aerospace parts [34,35]. Aluminum alloy 7475 with low-density and high-strength is the first material for lightweight parts and it is widely used in civil aircraft due to its good processability, good electrical and thermal conductivity. The cutting condition is dry cutting (see Table 1). 


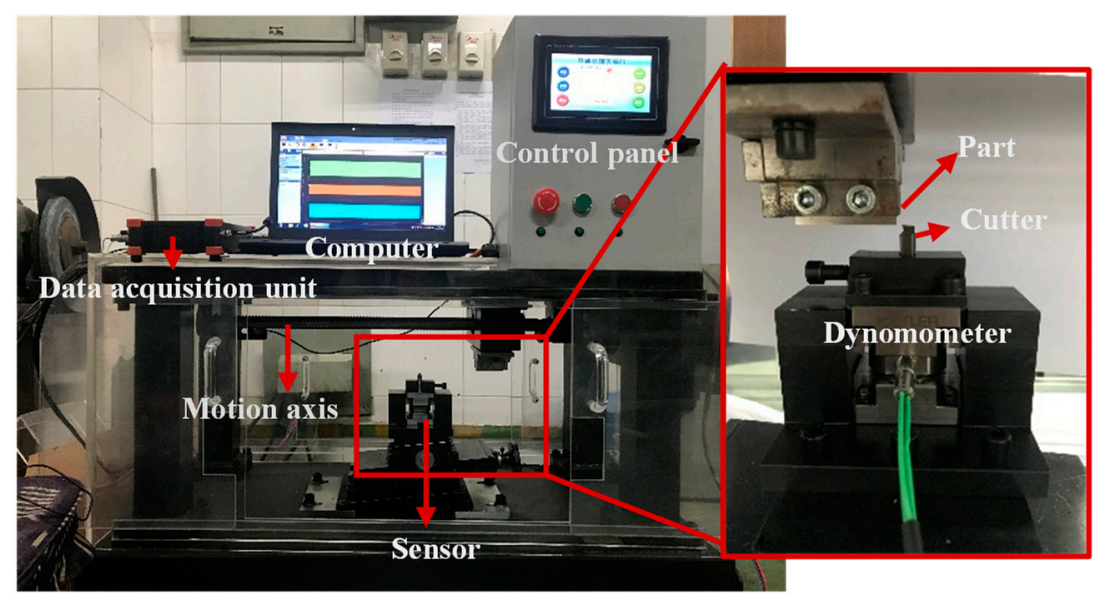

Figure 4. Setup of standard test table.

Table 1. Orthogonal cutting parameters.

\begin{tabular}{cccc}
\hline Test No. & $\boldsymbol{v}(\mathbf{m} / \mathbf{m i n})$ & $\boldsymbol{h}(\mathbf{m m})$ & $\boldsymbol{b}(\mathbf{m m})$ \\
\hline 1 & 40 & 0.08 & 1 \\
2 & 40 & 0.12 & 1 \\
3 & 40 & 0.16 & 1 \\
4 & 40 & 0.20 & 1 \\
\hline
\end{tabular}

In order to obtain accurate cutting force coefficients, the experiment uses four groups of cutting parameters, which carried out 10 experiments under the same cutting conditions. The cutting force data of the standard test table is shown in Figure 5, and the identified cutting force coefficients are shown in Table 2.

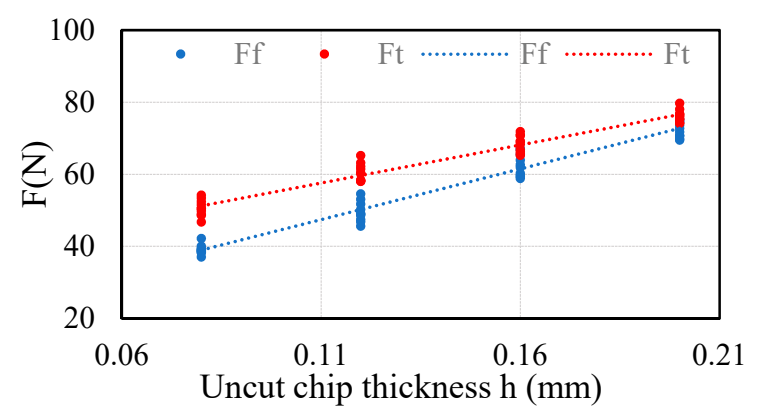

Figure 5. Cutting force of standard test table.

Table 2. Identified cutting force coefficients.

\begin{tabular}{cccc}
\hline$K_{t c}\left(\mathrm{~N} / \mathrm{mm}^{2}\right)$ & $K_{t e}(\mathrm{~N} / \mathrm{mm})$ & $K_{f c}\left(\mathrm{~N} / \mathrm{mm}^{2}\right)$ & $K_{f e}(\mathrm{~N} / \mathrm{mm})$ \\
\hline 211.4 & 34.32 & 281.78 & 16.417 \\
\hline
\end{tabular}

The milling experiment was performed on the YH850 3-axis machining center to obtain the cutting force data during the milling process, the force signal is measured by Kistler 9257B, which is a multi-component dynamometer. The workpiece material is aluminum alloy 7475. The tool is SGO S550, a 3-blade end mill. It is made of a new type of ultra-fine tungsten steel base metal with high wear resistance and strength. It is specially used for high hardness and high speed cutting applications. For the failure of sensors in $\mathrm{Z}$ direction, only data in $X$ and $Y$ axis will be processed. The cutting condition is dry cutting. The cutter geometry and cutting parameters are shown in Tables 3 and 4 . The experiment platform construction is shown in Figure 6. 
Table 3. Cutter geometry parameters.

\begin{tabular}{cccccc}
\hline Cutter & $\begin{array}{c}\text { Helical } \\
\text { Angle }\end{array}$ & $\begin{array}{c}\text { Diameter } \\
(\mathbf{m m})\end{array}$ & $\begin{array}{c}\text { Length of } \\
\text { Cutter }(\mathbf{m m})\end{array}$ & $\begin{array}{c}\text { Length of Cutting } \\
\text { Section }(\mathbf{m m})\end{array}$ & $\begin{array}{c}\text { Number of } \\
\text { Teeth }\end{array}$ \\
\hline A & $45^{\circ}$ & 12 & 75 & 36 & 3 \\
B & $45^{\circ}$ & 10 & 75 & 30 & 3 \\
\hline
\end{tabular}

Table 4. Cutting parameters for milling process.

\begin{tabular}{ccccc}
\hline Test No. & $\boldsymbol{a}_{\boldsymbol{p}} \mathbf{( \mathbf { m m } )}$ & $\boldsymbol{a}_{\boldsymbol{e}} \mathbf{( \mathbf { m m } )}$ & $\boldsymbol{n}(\mathbf{r p m})$ & $f(\mathbf{m m} \mathbf{m i n})$ \\
\hline 1 & 2 & 6 & 4000 & 120 \\
2 & 2 & 6 & 4000 & 180 \\
3 & 2 & 6 & 4000 & 240 \\
4 & 2 & 6 & 4000 & 300 \\
5 & 2 & 6 & 5000 & 150 \\
6 & 2 & 6 & 5000 & 225 \\
7 & 2 & 6 & 5000 & 300 \\
8 & 2 & 6 & 5000 & 375 \\
9 & 2 & 6 & 6000 & 180 \\
10 & 2 & 6 & 6000 & 270 \\
11 & 2 & 6 & 6000 & 360 \\
12 & 2 & 6 & 6000 & 450 \\
\hline
\end{tabular}

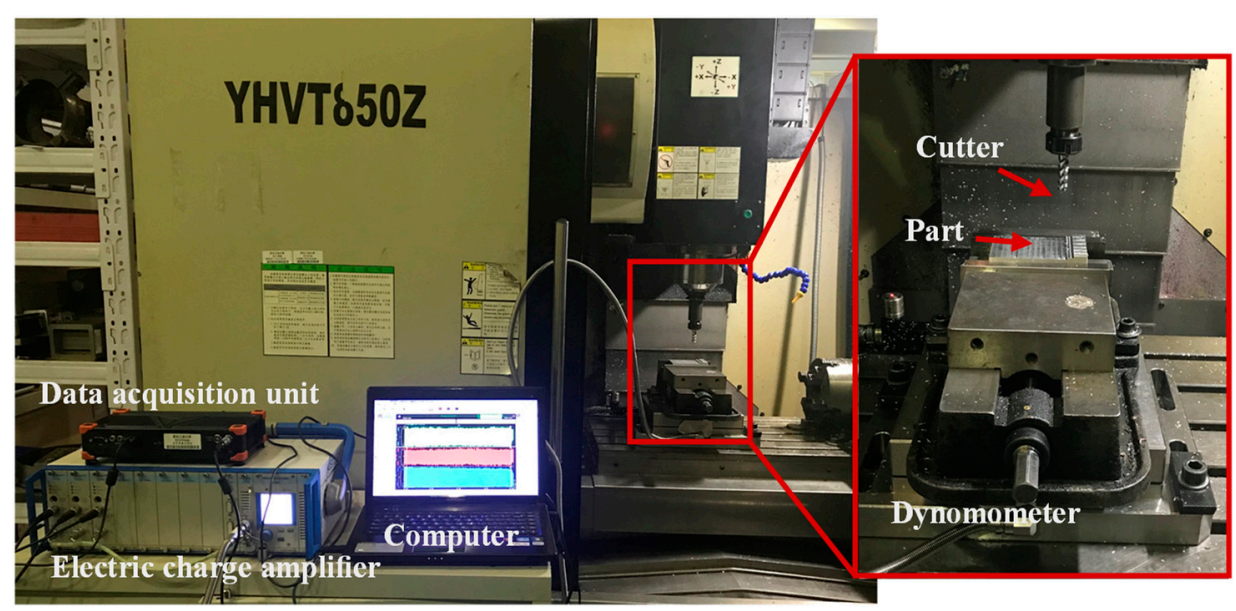

Figure 6. Setup of experiments.

\subsection{Comparison and Verification}

The standard cutting force is calculated by using the cutting force coefficients, which are obtained from the standard test table (Table 2). Through the transfer model (Equations (1)-(5)), the milling force under different parameters can be calculated. Several typical results of standard and measurement are compared (Figure 7). Although the cutting conditions and machine tools have changed, the cutting force measured during the milling process (called the measuring force) and the cutting force transferred from the standard cutting force (called the standard force) are still relatively close. However, there are many differences between the standard force and the measured force, especially in the peak and valley positions of cutting force. The reason for this phenomenon is that the vibration of the tool causes the cutting thickness in the actual machining to change, which in turn causes the cutting force to change.

In addition, it is found in Figure 7 that the measured force is close to the standard force at the cutting in and cutting out stages of each tooth, and there is a huge difference between them at the middle cutting stage of each tooth. For example, Figure 7a shows the cutting forces in the second group of experiments. At the initial cutting in of the tool, the 
standard value of the cutting force is close to the measured single. When the chip thickness of each tooth reaches the maximum, the standard value and the measured value are quite different. The rule of variation is also applicable to Figure $7 \mathrm{~b}, \mathrm{c}$. Therefore, the influence of the tool system cannot be ignored in the conversion of cutting force.
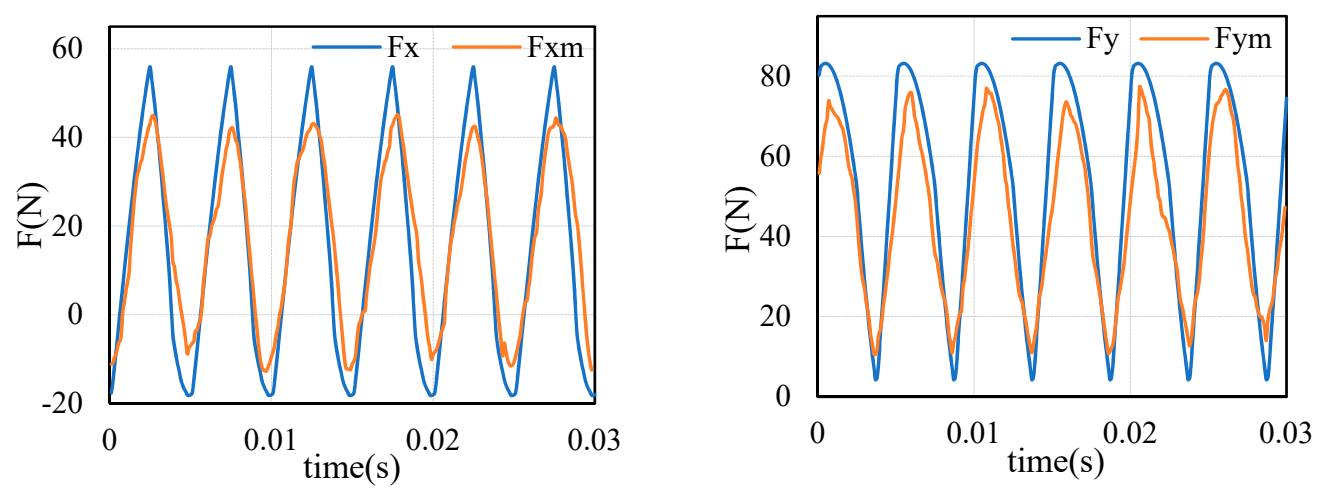

(a)
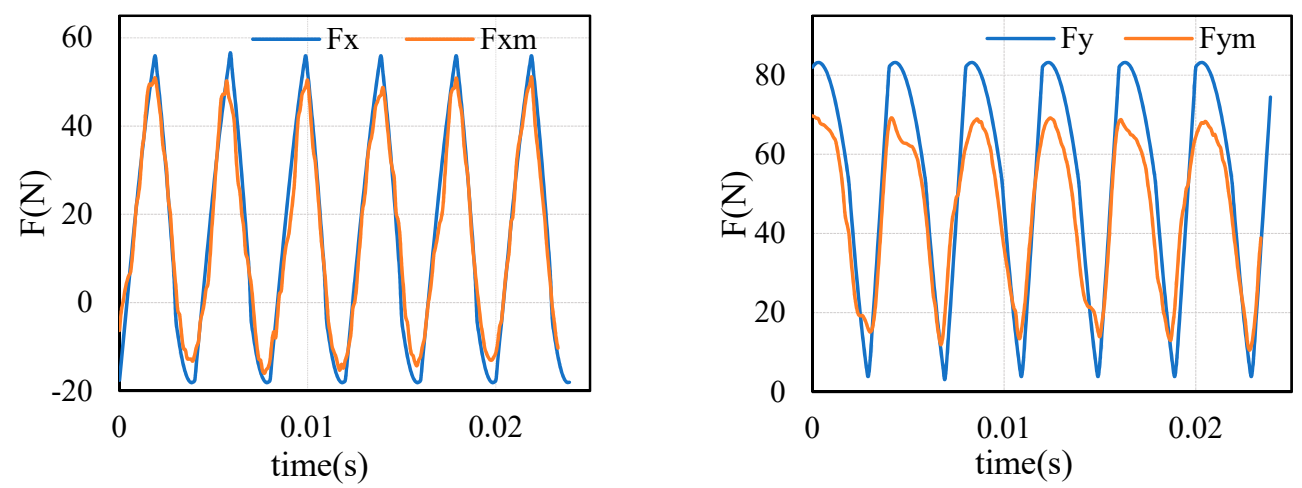

(b)
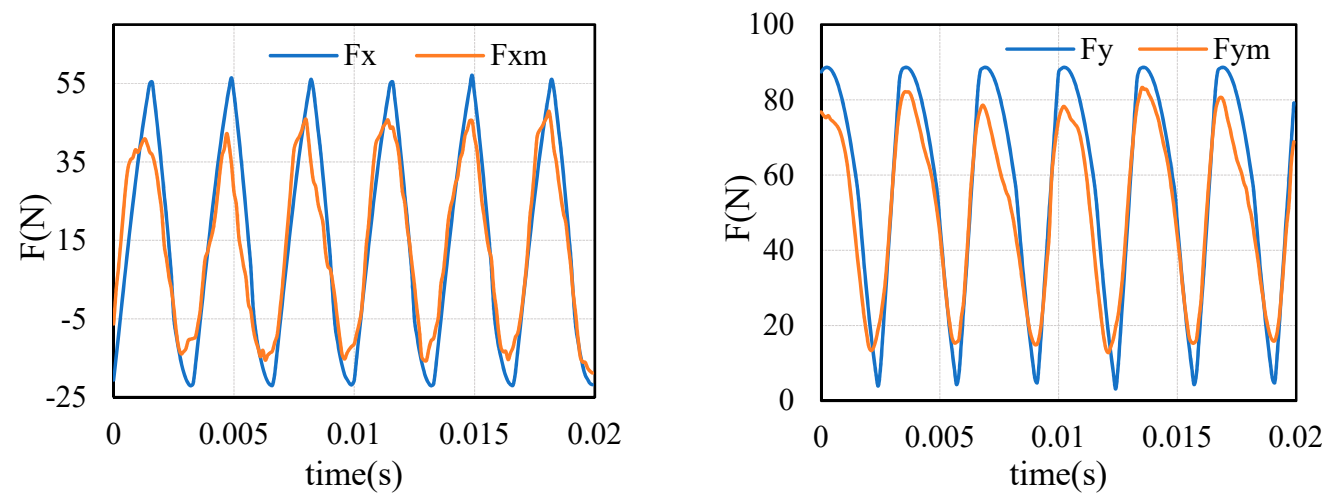

(c)

Figure 7. Comparison of measured cutting force and standard cutting force: (a) measured vs. standard (Test 2); (b) measured vs. standard (Test 6); (c) measured vs. standard (Test 12).

In order to identify the difference of the cutting force, the influence of the dynamic parameters of the tool is considered, which can be obtained by hammering test, see Table 5 . 
Table 5. Stiffness parameters of test tool (cutter A)

\begin{tabular}{ccc}
\hline$m_{x} / m_{y}(\mathbf{k g})$ & $c_{x} / c_{y}(\mathrm{~N} /(\mathrm{m} / \mathrm{s}))$ & $k_{x} / k_{y}(\mathrm{~N} / \mathrm{m})$ \\
\hline $2.6730 \times 10^{7}$ & 235.8167 & 0.6891 \\
\hline
\end{tabular}

This paper uses the orthogonal cutting for identification to eliminate the influence of external factors on the cutting force coefficients. Therefore, in the process of tool rotary cutting, the measured cutting force always adds the influence of tool dynamic parameters. As the cutting thickness changes, the impact is constantly changing. Under the cutting parameters in Table 3, the cutting force and tool displacement during machining are collected. Figure 8 shows a section of tool displacement signal.

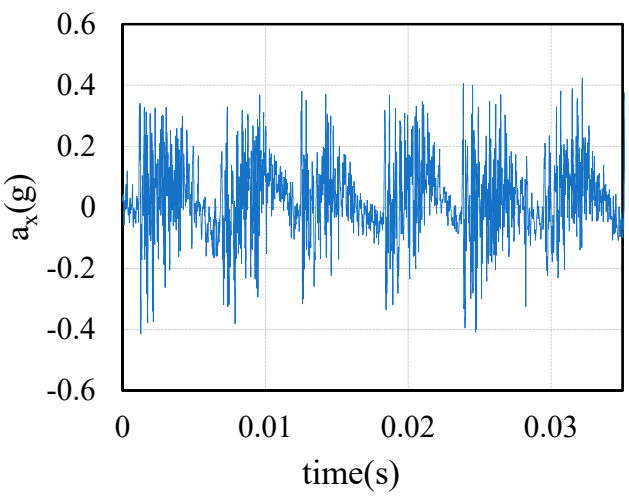

(a)

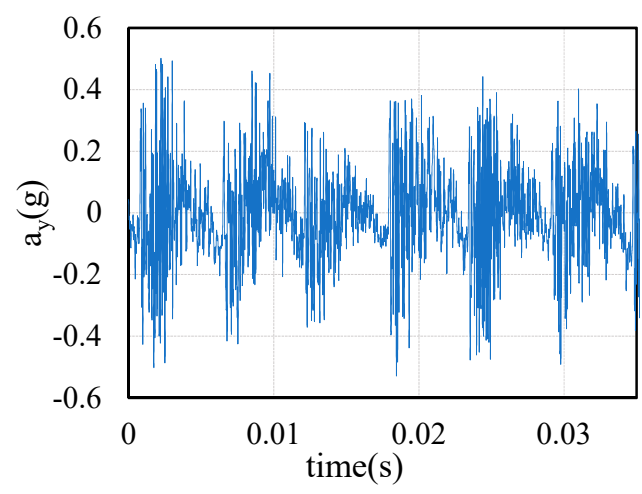

(b)

Figure 8. Acceleration signals from Test 2: (a) X direction; (b) Y direction.

The dynamic parameters and displacement signals of the tool are substituted into Equations (8) and (10). After the influence of the tool system is superimposed, the measured cutting force is compared with the predicted cutting force calculated by proposed method. The results are shown in Figure 9. Considering the inhomogeneity of material and the contingency of measurement, the predicted value is in good agreement with the measured value. Obviously, the predicted value is distributed around the measurement, which shows that the model is reasonable and correct conclusions can be obtained. In Figure 9, the peak and valley of cutting force in $X$ direction are similar in values, and the same in $Y$ direction.
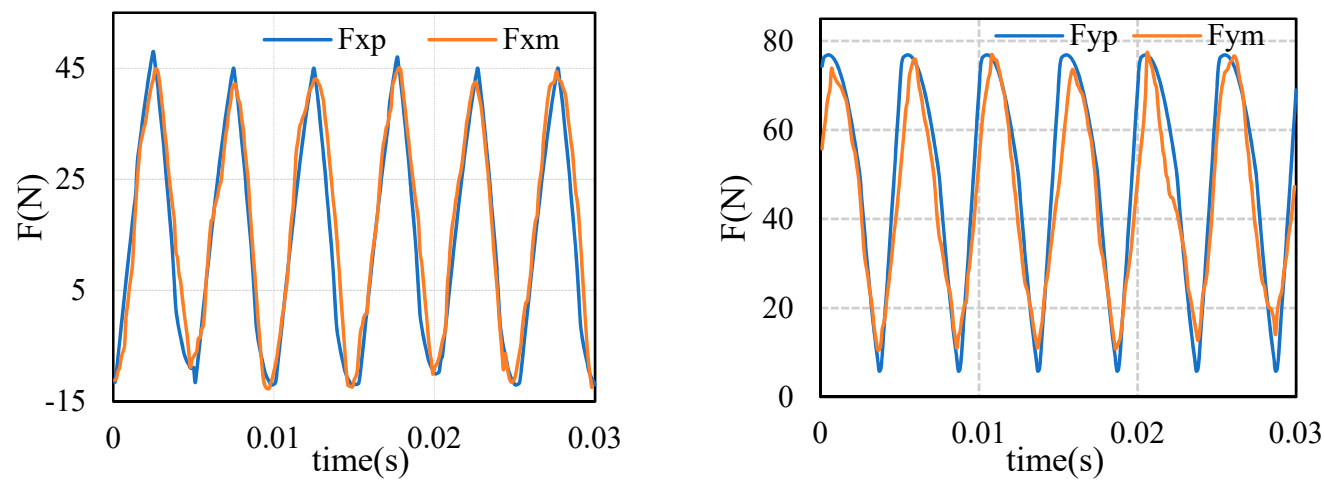

(a)

Figure 9. Cont. 

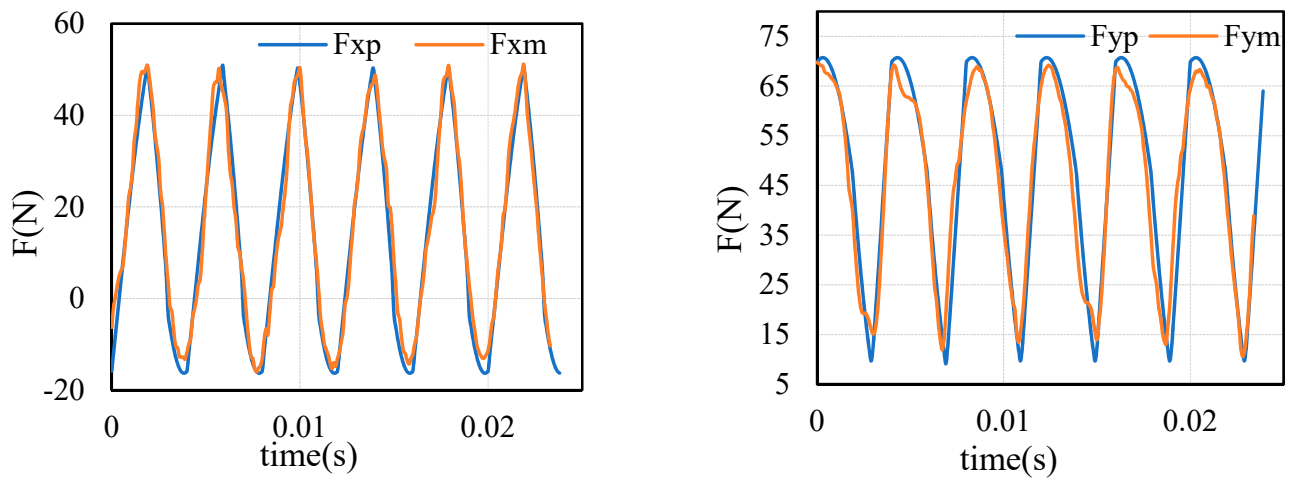

(b)
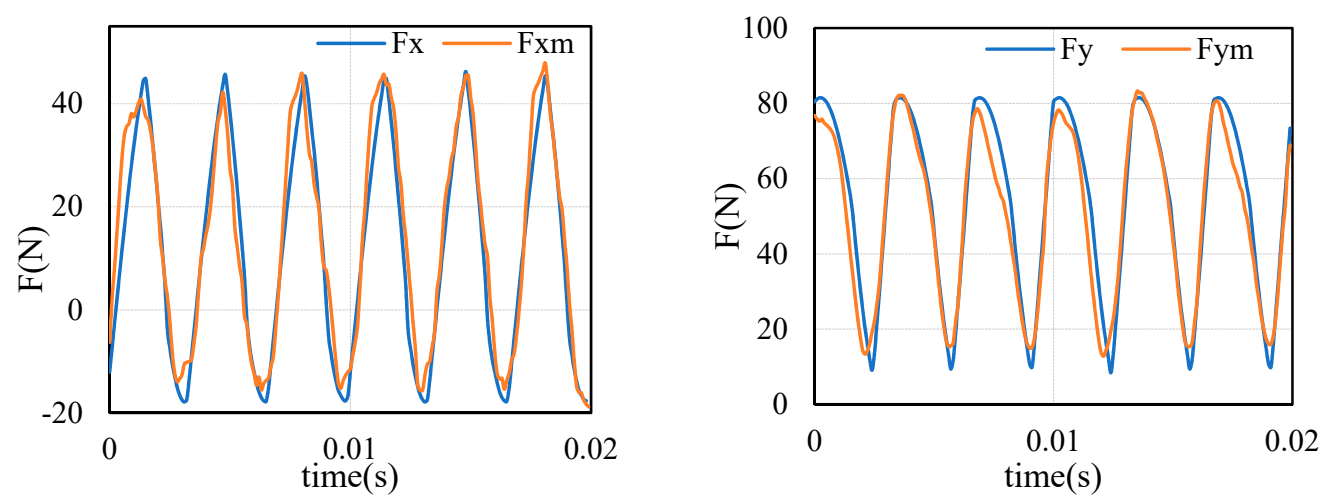

(c)

Figure 9. Comparison of measured cutting force and predicted cutting force: (a) measured vs. predicted (Test 2); (b) measured vs. predicted (Test 6); (c) measured vs. predicted (Test 12).

By comparing the standard value, measured value and predicted value of cutting force, the effectiveness of the proposed model can be seen. As shown in Figure 10, the yellow surface represents the standard cutting force under different cutting parameters, and the dark blue surface is at the bottom, which indicates the measured cutting force. The difference between the two surfaces is large, indicating that the standard cutting data has not been considered tool system impact in the actual machining. The light blue surface in the middle is the predicted value of the model proposed in this paper, and it is found to be closer to the measured value. The results show that the method of superimposing too system influence on standard cutting force is correct and feasible.

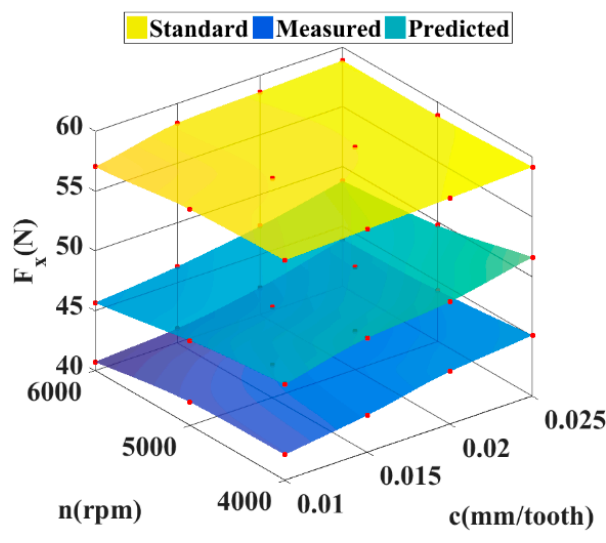

(a)

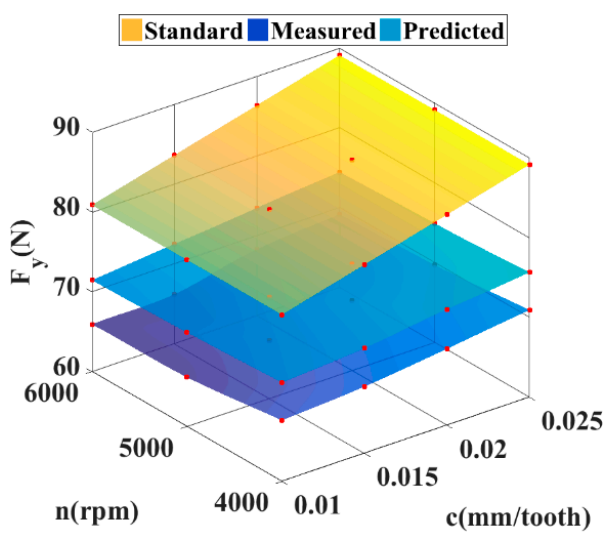

(b)

Figure 10. Comparison of cutting forces under different cutting parameters: (a) X direction; (b) Y direction. 
The detailed analysis is as follows: the errors calculated by Equations (12) and (13) are shown in Figure 11.

$$
\begin{aligned}
& \text { error }_{\text {before }}=\left|\frac{F_{\text {standard }}-F_{\text {measured }}}{F_{\text {measured }}}\right| \\
& \text { error }_{\text {after }}=\left|\frac{F_{\text {predicted }}-F_{\text {measured }}}{F_{\text {measured }}}\right|
\end{aligned}
$$

The error between the standard and the measured value is obviously higher than the error between the predicted and the measured value through Figure 11, which indicates that the accuracy of the transition model is improved after the influence of the tool system is superimposed. The applicability of the proposed model is validated in a series of experiments with different cutting parameters.
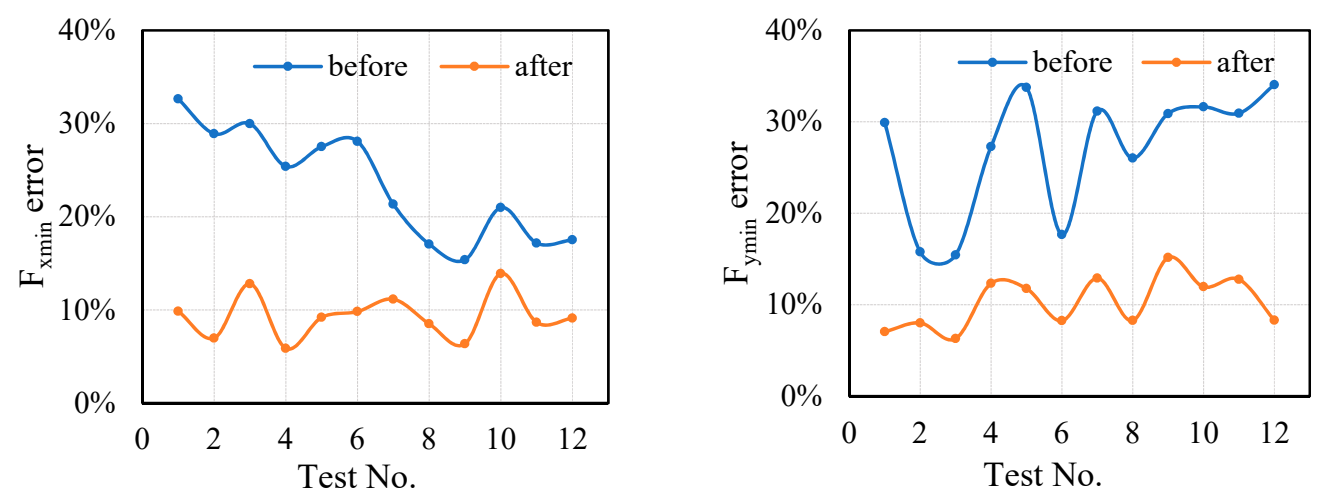

(a)
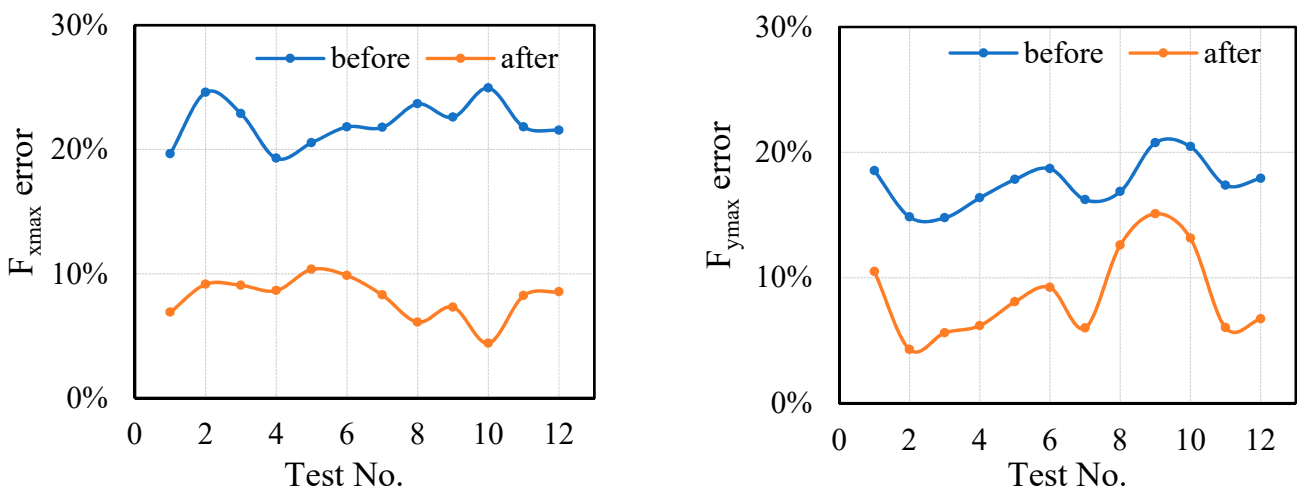

(b)

Figure 11. Data transition error before and after considering the influence of tool system: (a) Cutting force transition error in $\mathrm{X}$ direction; (b) Cutting force transition error in $\mathrm{Y}$ direction.

The average value and deviation are shown in Table 6 . The data in Table 6 also show that the conversion error of cutting force using proposed model is close to the measured cutting force. It can be found that, when ignoring the influence of the tool system, the cutting force conversion error is large, even exceeding $30 \%$ (Test No. 1, 5 etc.). The cutting force conversion error of the method proposed in this paper is significantly reduced, and the error is about $10 \%$. 
Table 6. Error value of data transition before and after considering the influence of tool system.

\begin{tabular}{|c|c|c|c|c|c|c|}
\hline Test No. & & Before & After & & Before & After \\
\hline \multirow{2}{*}{1} & $F_{x \max }$ & $19.65 \%$ & $6.90 \%$ & $F_{y \max }$ & $18.54 \%$ & $10.48 \%$ \\
\hline & $\mathrm{F}_{\mathrm{xmin}}$ & $32.63 \%$ & $9.84 \%$ & $\mathrm{~F}_{\mathrm{ymin}}$ & $29.91 \%$ & $7.03 \%$ \\
\hline \multirow{2}{*}{2} & $F_{x \max }$ & $24.59 \%$ & $9.15 \%$ & $\mathrm{~F}_{\text {ymax }}$ & $14.85 \%$ & $4.28 \%$ \\
\hline & $\mathrm{F}_{\mathrm{xmin}}$ & $28.91 \%$ & $6.97 \%$ & $\mathrm{~F}_{\mathrm{ymin}}$ & $15.77 \%$ & $8.00 \%$ \\
\hline \multirow{2}{*}{3} & $\mathrm{~F}_{\mathrm{xmax}}$ & $22.89 \%$ & $9.07 \%$ & $\mathrm{~F}_{\text {ymax }}$ & $14.77 \%$ & $5.60 \%$ \\
\hline & $\mathrm{F}_{\mathrm{xmin}}$ & $29.99 \%$ & $12.81 \%$ & $\mathrm{~F}_{\mathrm{ymin}}$ & $15.44 \%$ & $6.29 \%$ \\
\hline \multirow{2}{*}{4} & $\mathrm{~F}_{\mathrm{x} \max }$ & $19.29 \%$ & $8.64 \%$ & $\mathrm{~F}_{\text {ymax }}$ & $16.37 \%$ & $6.17 \%$ \\
\hline & $\mathrm{F}_{\mathrm{xmin}}$ & $25.40 \%$ & $5.87 \%$ & $\mathrm{~F}_{\mathrm{ymin}}$ & $27.29 \%$ & $12.33 \%$ \\
\hline \multirow{2}{*}{5} & $F_{x \max }$ & $20.54 \%$ & $10.35 \%$ & $\mathrm{~F}_{\text {ymax }}$ & $17.84 \%$ & $8.08 \%$ \\
\hline & $\mathrm{F}_{\mathrm{xmin}}$ & $27.51 \%$ & $9.19 \%$ & $\mathrm{~F}_{\mathrm{ymin}}$ & $33.76 \%$ & $11.76 \%$ \\
\hline \multirow{2}{*}{6} & $\mathrm{~F}_{\mathrm{xmax}}$ & $21.81 \%$ & $9.86 \%$ & $\mathrm{~F}_{\text {ymax }}$ & $18.70 \%$ & $9.22 \%$ \\
\hline & $\mathrm{F}_{\mathrm{xmin}}$ & $28.08 \%$ & $9.82 \%$ & $\mathrm{~F}_{\mathrm{ymin}}$ & $17.67 \%$ & $8.24 \%$ \\
\hline \multirow{2}{*}{7} & $\mathrm{~F}_{\mathrm{xmax}}$ & $21.77 \%$ & $8.29 \%$ & $\mathrm{~F}_{\text {ymax }}$ & $16.22 \%$ & $5.99 \%$ \\
\hline & $\mathrm{F}_{\mathrm{xmin}}$ & $21.34 \%$ & $11.15 \%$ & $\mathrm{~F}_{\mathrm{ymin}}$ & $31.15 \%$ & $12.91 \%$ \\
\hline \multirow{2}{*}{8} & $F_{x \max }$ & $23.67 \%$ & $6.11 \%$ & $\mathrm{~F}_{\text {ymax }}$ & $16.87 \%$ & $12.60 \%$ \\
\hline & $\mathrm{F}_{\mathrm{xmin}}$ & $17.06 \%$ & $8.51 \%$ & $\mathrm{~F}_{\mathrm{ymin}}$ & $26.02 \%$ & $8.26 \%$ \\
\hline \multirow{2}{*}{9} & $F_{x \max }$ & $22.60 \%$ & $7.31 \%$ & $\mathrm{~F}_{\text {ymax }}$ & $20.76 \%$ & $15.10 \%$ \\
\hline & $\mathrm{F}_{\mathrm{xmin}}$ & $15.38 \%$ & $6.36 \%$ & $\mathrm{~F}_{\mathrm{ymin}}$ & $30.89 \%$ & $15.16 \%$ \\
\hline \multirow{2}{*}{10} & $\mathrm{~F}_{\mathrm{xmax}}$ & $24.94 \%$ & $4.41 \%$ & $\mathrm{~F}_{\text {ymax }}$ & $20.46 \%$ & $13.15 \%$ \\
\hline & $\mathrm{F}_{\mathrm{xmin}}$ & $20.99 \%$ & $13.90 \%$ & $\mathrm{~F}_{\text {ymin }}$ & $31.63 \%$ & $11.96 \%$ \\
\hline \multirow{2}{*}{11} & $F_{x \max }$ & $21.81 \%$ & $8.24 \%$ & $F_{\text {ymax }}$ & $17.37 \%$ & $6.02 \%$ \\
\hline & $\mathrm{F}_{\mathrm{xmin}}$ & $17.17 \%$ & $8.65 \%$ & $\mathrm{~F}_{\mathrm{ymin}}$ & $30.93 \%$ & $12.77 \%$ \\
\hline \multirow{2}{*}{12} & $F_{x \max }$ & $21.54 \%$ & $8.55 \%$ & $\mathrm{~F}_{\text {ymax }}$ & $17.92 \%$ & $6.72 \%$ \\
\hline & $\mathrm{F}_{\mathrm{xmin}}$ & $17.52 \%$ & $9.11 \%$ & $\mathrm{~F}_{\mathrm{ymin}}$ & $34.05 \%$ & $8.29 \%$ \\
\hline
\end{tabular}

Since the tool system influence is the measured acceleration signal, the change is not regular, so the actual cutting thickness of each tooth is different in the tool rotary cutting. In order to further verify the accuracy of the model, the error of cutting force of each tooth under different cutting parameters should be analyzed. Figure 12 shows the error analysis of the second set of experiments. The predicted cutting force obtained by proposed model not only reduce the error of average cutting force, but also can be applied to the real-time cutting force of each tooth. The error of cutting force per tooth decreases from $20-30 \%$ to about $10 \%$, indicating that the predicted cutting force of the proposed model is close to the measured cutting force. Although the error comes from the randomness of tool acceleration and measurement data, the prediction error is acceptable in data conversion.

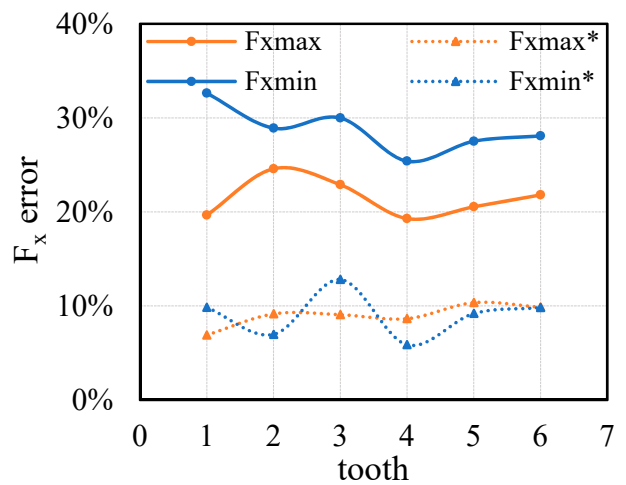

(a)

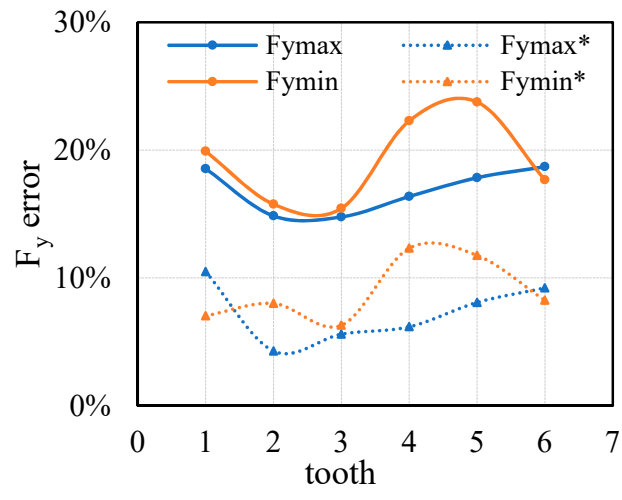

(b)

Figure 12. Data transition error comparison of each tooth cutter from Test 2: (a) Comparison of $X$ direction error; (b) Comparison of $Y$ direction error.

In order to further verify the data conversion method, the stiffness parameters of cutter are changed by changing the diameter of cutter, whose stiffness parameters are 
shown in Table 7. Cutter B is used. The experimental conditions are shown in Table 8. The acceleration signal collected in test 1 is shown in Figure 13.

Table 7. Stiffness parameters of cutter B.

\begin{tabular}{ccc}
\hline$m_{x} / m_{y}(\mathbf{k g})$ & $c_{x} / c_{y}(\mathrm{~N} /(\mathrm{m} / \mathrm{s}))$ & $k_{x} / k_{y}(\mathrm{~N} / \mathrm{m})$ \\
\hline $1.5374 \times 10^{7}$ & 235.8167 & 0.6891 \\
\hline
\end{tabular}

Table 8. Cutting conditions for verification tests.

\begin{tabular}{ccccc}
\hline Test No. & $\boldsymbol{a}_{\boldsymbol{p}} \mathbf{( \mathbf { m m } )}$ & $\boldsymbol{a}_{\boldsymbol{e}} \mathbf{( \mathbf { m m } )}$ & $\boldsymbol{n} \mathbf{( \mathbf { r p m } )}$ & $\boldsymbol{f} \mathbf{( \mathbf { m m } / \mathbf { m i n } )}$ \\
\hline 1 & 2 & 6 & 4000 & 120 \\
2 & 2 & 6 & 4000 & 240 \\
3 & 2 & 6 & 5000 & 150 \\
4 & 2 & 6 & 5000 & 300 \\
5 & 2 & 6 & 6000 & 180 \\
6 & 2 & 6 & 6000 & 360 \\
\hline
\end{tabular}

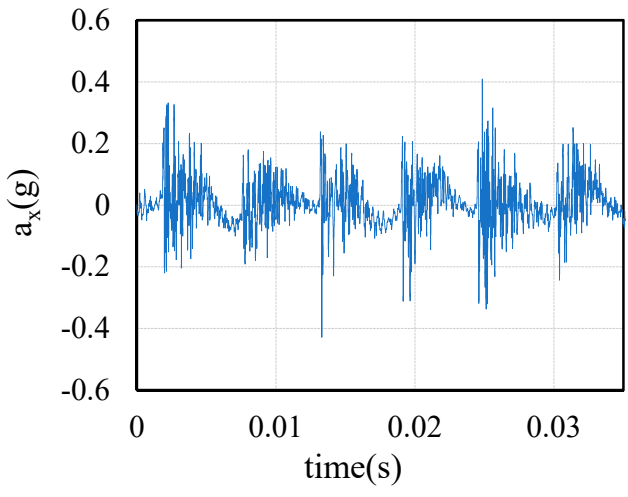

(a)

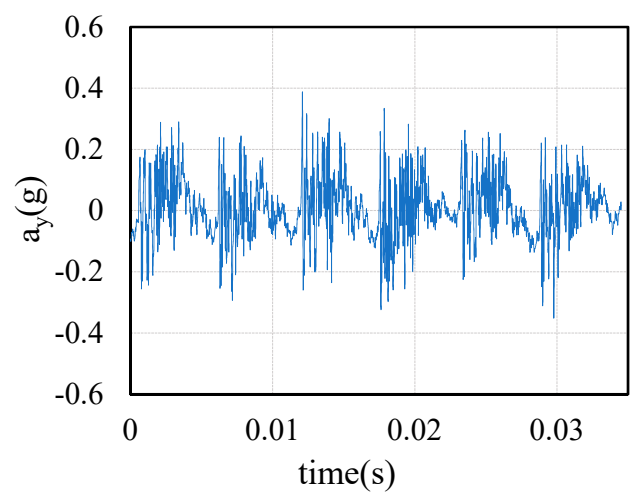

(b)

Figure 13. Acceleration signals from Test 1: (a) X direction; (b) Y direction.

Then, the predicted cutting force are calculated. Result of cutting force comparison from test 1 is shown in Figure 14. The error comparison of all tests is shown in Figure 15.

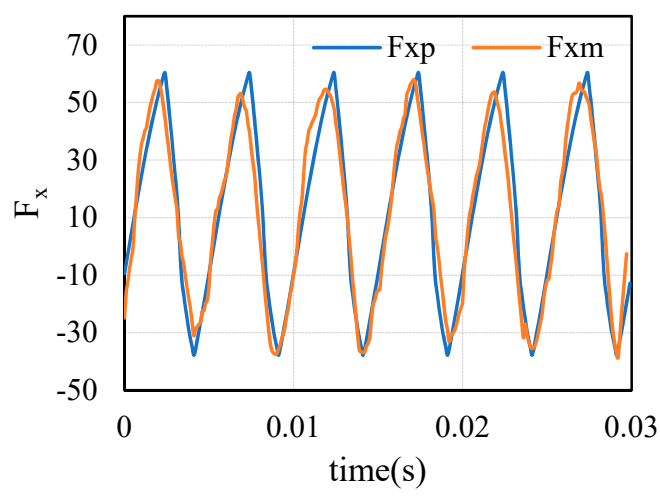

(a)

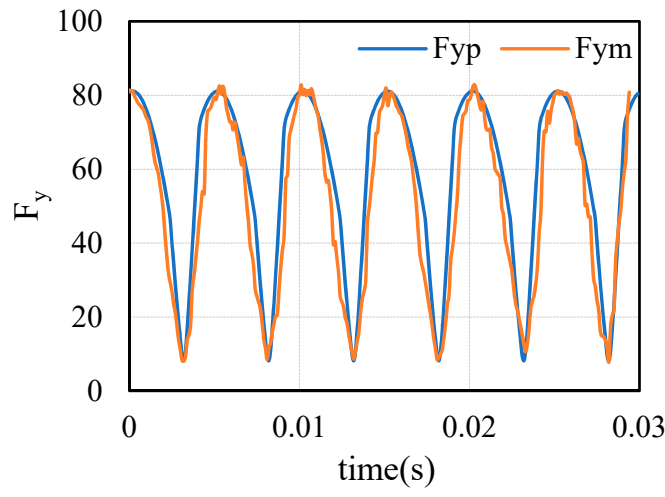

(b)

Figure 14. Comparison of measured cutting force and predicted cutting force in test 1 . 


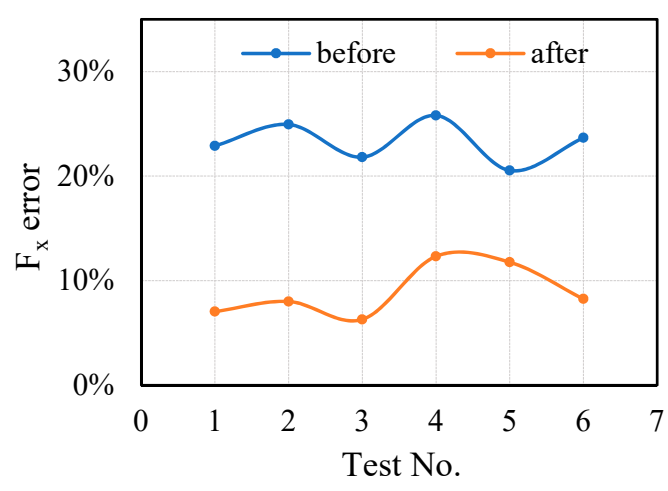

(a)

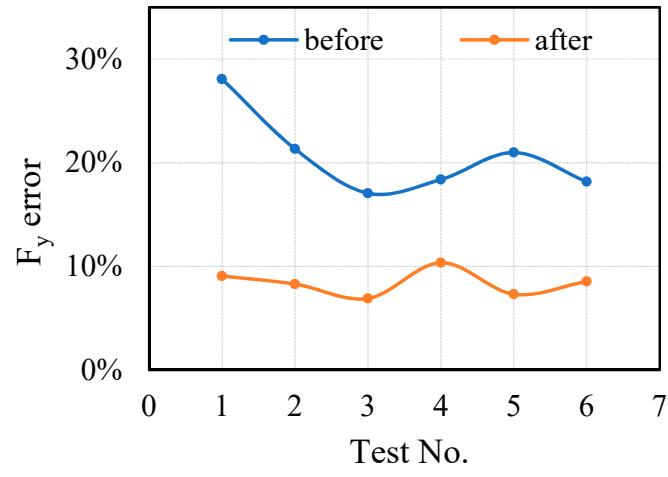

(b)

Figure 15. Data transition error before and after considering the influence of tool system: (a) Cutting force transition error in $\mathrm{X}$ direction; (b) Cutting force transition error in $\mathrm{Y}$ direction.

Through the comparative analysis of cutting force and error, it is found that except repeating the occurred phenomena in previous section, here are few new anomalies in this section. The predicted cutting force obtained by the proposed method has high accuracy.

\section{Conclusions}

In this paper, a cutting force transition model considering the influence of the machine tool system is proposed, which can realize the transition from standard cutting data to actual machining data. Comparative experiments show that the accuracy of data transition by the proposed model is improved from about $30 \%$ to about $10 \%$, which verifies the effectiveness of the method.

The practical significance of proposed method lies in the following. (1) The current cutting performance test data are obtained under specific cutting conditions, and the obtained cutting data have no standard to be based on and cannot be effectively applied. In this paper, the standard cutting data are obtained with orthogonal cutting by a special standard test table, which can be used as the basis for data transition. (2) There is no mapping from basic data to milling cutting data, which means the basic cutting data cannot be applied to actual parts production. In this paper, the influence of the tool system is considered in the data transition, and the effective data transition is realized.

For potential future research, firstly, we will further study the data transition method between heterogeneous process system and transfer the existing large amount of reliable data to the equipment with little information; secondly, we will improve the standard test table, and embed sensors to obtain more cutting process parameters, so as to obtain more complete information reflection. Moreover, better analysis and optimization of the process can improve the processing efficiency.

Author Contributions: Conceptualization, X.C., D.Z. and B.C.; methodology, X.C.; validation, X.C. and Q.W.; formal analysis, X.C. and Q.W.; investigation, X.C. and Q.W.; data curation, X.C.; writingoriginal draft preparation, X.C.; writing—review and editing, X.C. and Q.W.; supervision, D.Z.; project administration, D.Z.; funding acquisition, D.Z. All authors have read and agreed to the published version of the manuscript.

Funding: This research was funded by [the National Natural Science Foundation of China] grant number [No. 51575453].

Conflicts of Interest: The authors declare no conflict of interest. 


\section{References}

1. Tuysuz, O.; Altintas, Y.; Feng, H.Y. Prediction of cutting forces in three and five-axis ball-end milling with tool indentation effect. Int. J. Mach. Tools Manuf. 2013, 66, 66-81. [CrossRef]

2. Rigelsford, J. Manufacturing Automation: Metal Cutting Mechanics, Machine Tool Vibrations, and CNC Design. Ind. Robot 2012, 31, B84. [CrossRef]

3. Grossi, N. Accurate and fast measurement of specific cutting force coefficients changing with spindle speed. Int. J. Precis. Eng. Manuf. 2017, 18, 1173-1180. [CrossRef]

4. Rosenthal, O.; Hintze, W.; Möller, C. Assessment of tool holder performance in roughing with end mills. Prod. Eng. 2020, 14, 253-263. [CrossRef]

5. Muñoz-Escalona, P.; Shokrani, A.; Newman, S.T. Influence of cutting environments on surface integrity and power consumption of austenitic stainless steel. Robot. Comput. Integr. Manuf. 2015, 36, 60-69. [CrossRef]

6. Schorník, V.; Daňa, M.; Zetková, I. The influence of the cutting conditions on the machined surface quality when the CFRP is machined. Procedia Eng. 2015, 100, 1270-1276. [CrossRef]

7. Mattei, L.; Di Puccio, F. Influence of the wear partition factor on wear evolution modelling of sliding surfaces. Int. J. Mech. Sci. 2015, 99, 72-88. [CrossRef]

8. Rimpault, X.; Chatelain, J.F.; Klemberg-Sapieha, J.E.; Balazinski, M. Tool wear and surface quality assessment of CFRP trimming using fractal analyses of the cutting force signals. CIRP J. Manuf. Sci. Technol. 2017, 16, 72-80. [CrossRef]

9. Taner, T.L.; Ömer, Ö.; Erhan, B. Generalized cutting force model in multi-axis milling using a new engagement boundary determination approach. Int. J. Adv. Manuf. Technol. 2015, 77, 341-355. [CrossRef]

10. Zhu, Z.; Yan, R.; Peng, F.; Duan, X.; Zhou, L.; Song, K.; Guo, C. Parametric chip thickness model based cutting forces estimation considering cutter runout of five-axis general end milling. Int. J. Mach. Tools Manuf. 2016, 101, 35-51. [CrossRef]

11. Zhu, Z.; Peng, F.; Yan, R.; Li, Z.; Wu, J.; Tang, X.; Chen, C. Influence Mechanism of Machining Angles on Force Induced Error and Their Selection in Five Axis Bullnose End Milling. Chin. J. Aeronaut. 2020, 33, 3447-3459. [CrossRef]

12. Sun, Y.; Jiang, S. Predictive modeling of chatter stability considering force-induced deformation effect in milling thin-walled parts. Int. J. Mach. Tools Manuf. 2018, 135, 38-52. [CrossRef]

13. Sahoo, P.; Pratap, T.; Patra, K. A hybrid modelling approach towards prediction of cutting forces in micro end milling of Ti-6Al-4V titanium alloy. Int. J. Mech. Sci. 2019, 150, 495-509. [CrossRef]

14. Zhang, X.; Zhang, J.; Pang, B.; Zhao, W. An accurate prediction method of cutting forces in 5-axis flank milling of sculptured surface. Int. J. Mach. Tools Manuf. 2016, 104, 26-36. [CrossRef]

15. Li, G.; Du, S.; Huang, D.; Zhao, C.; Deng, Y. Dynamics modeling-based optimization of process parameters in face milling of workpieces with discontinuous surfaces. J. Manuf. Sci. Eng. 2019, 141. [CrossRef]

16. Wang, S.B.; Geng, L.; Zhang, Y.F.; Liu, G.; Ng, T.E. Cutting force prediction for five-axis ball-end milling considering cutter vibrations and run-out. Int. J. Mech. Sci. 2015, 96, 206-215. [CrossRef]

17. Zhu, K.; Zhang, Y. Modeling of the instantaneous milling force per tooth with tool run-out effect in high speed ball-end milling. Int. J. Mach. Tools Manuf. 2017, 118, 37-48. [CrossRef]

18. Li, Y.; Zhang, G.; Wang, Y.; Zhang, X.; Ran, Y. Research on reliability allocation technology for NC machine tool meta-action. Qual. Reliab. Eng. Int. 2019, 35, 2016-2044. [CrossRef]

19. Altintas, Y.; Aslan, D. Integration of virtual and on-line machining process control and monitoring. CIRP Ann. 2017, 66, 349-352. [CrossRef]

20. Postel, M.; Özsahin, O.; Altintas, Y. High speed tooltip FRF predictions of arbitrary tool-holder combinations based on operational spindle identification. Int. J. Mach. Tools Manuf. 2018, 129, 48-60. [CrossRef]

21. Zhang, J.; Li, J.; Xie, Z.; Du, C.; Gui, L.; Zhao, W. Rapid dynamics prediction of tool point for bi-rotary head five-axis machine tool. Precis. Eng. 2017, 48, 203-215. [CrossRef]

22. Ji, Y.; Bi, Q.; Zhang, S.; Wang, Y. A new receptance coupling substructure analysis methodology to predict tool tip dynamics. Int. J. Mach. Tools Manuf. 2018, 126, 18-26. [CrossRef]

23. Chen, G.; Li, Y.; Liu, X. Pose-dependent tool tip dynamics prediction using transfer learning. Int. J. Mach. Tools Manuf. 2019, 137, 30-41. [CrossRef]

24. Liu, X.; Li, Y.; Chen, G. Multimode tool tip dynamics prediction based on transfer learning. Robot. Comput. Integr. Manuf. 2019, 57, 146-154. [CrossRef]

25. Yue, C.; Gao, H.; Liu, X.; Liang, S.T.; Wang, L. A review of chatter vibration research in milling. Chin. J. Aeronaut. 2019, 32, 215-242. [CrossRef]

26. Santos, M.C.; Machado, A.R.; Sales, W.F.; Barrozo, M.A.S.; Ezugwu, E.O. Machining of aluminum alloys: A review. Int. J. Adv. Manuf. Technol. 2016, 86, 3067-3080. [CrossRef]

27. Grossi, N.; Sallese, L.; Scippa, A.; Campatelli, G. Speed-varying cutting force coefficient identification in milling. Precis. Eng. 2015, 42, 321-334. [CrossRef]

28. Xu, K.; Wang, J.; Chu, C.H.; Tang, K. Cutting force and machine kinematics constrained cutter location planning for five-axis flank milling of ruled surfaces. J. Comput. Des. Eng. 2017, 4, 203-217. [CrossRef]

29. Dikshit, M.K.; Puri, A.B.; Maity, A. Analysis of rotational speed variations on cutting force coefficients in high-speed ball end milling. J. Braz. Soc. Mech. Sci. Eng. 2017, 39, 3529-3539. [CrossRef] 
30. Schwenzer, M.; Auerbach, T.; Döbbeler, B.; Bergs, T. Comparative study on optimization algorithms for online identification of an instantaneous force model in milling. Int. J. Adv. Manuf. Technol. 2019, 101, 2249-2257. [CrossRef]

31. Wan, M.; Yin, W.; Zhang, W.H.; Liu, H. Improved inverse filter for the correction of distorted measured cutting forces. Int. J. Mech. Sci. 2017, 120, 276-285. [CrossRef]

32. Liu, X.; Gao, H.; Yue, C.; Li, R.; Jiang, N.; Liang, L. Investigation of the milling stability based on modified variable cutting force coefficients. Int. J. Adv. Manuf. Technol. 2018, 96, 2991-3002. [CrossRef]

33. Wang, C.; Zhang, X.; Qiao, B.; Cao, H.; Chen, X. Dynamic Force Identification in Peripheral Milling Based on CGLS Using Filtered Acceleration Signals and Averaged Transfer Functions. J. Manuf. Sci. Eng. 2019, 141. [CrossRef]

34. Liu, B.; Peng, C.; Wang, R.; Wang, X.; Li, T. Recent development and prospects for giant plane aluminum alloys. Chin. J. Nonferrous Met. 2010, 9, 1705-1715.

35. She, H.; Shu, D.; Chu, W.; Wang, J.; Sun, B.d. Effects of Fe and Si Impurities on the Microstructure and Properties of $7 \times \times \times$ High Strength Aircraft Aluminum Alloys. J. Mater. Eng. 2013, 3, 92-98. 